\title{
TEORES DE MACRONUTRIENTES E DE COLESTEROL EM DIFERENTES TIPOS DE OVOS
}

\author{
MIRIAN SALVADOR * \\ PATRICIA DALLA SANTA **
}

\begin{abstract}
Avaliou-se o teor de macronutrientes e de colesterol em ovos vermelhos de galinhas de granja e caipiras, ovos brancos de galinhas de granja, ovos brancos enriquecidos com PUFA ômega-3, ovos brancos com teor reduzido de colesterol e ovos de codorna. Os resultados mostraram que não houve diferença estatística significativa entre o conteúdo de proteínas e de colesterol dos ovos analisados. Os ovos de codorna apresentaram o maior teor de lipídios entre as amostras ensaiadas.
\end{abstract}

PALAVRAS-CHAVE: OVOS; COLESTEROL.

\section{INTRODUÇÃO}

Os ovos constituem-se em alimento barato e nutritivo que faz parte da alimentação da população brasileira de todos os níveis sociais. A clara representa cerca de $60 \%$ do peso do ovo, sendo rica em água e proteínas, principalmente albumina. A gema, responsável por 30-32\% do peso total do ovo é formada basicamente por água, proteínas e lipídios. Entre estes últimos encontra-se o colesterol que, quando consumido em excesso, está associado ao aumento da incidência de doenças cardiovasculares. A casca do ovo representa os restantes $10 \%$ de seu peso total (MADRID, 1991). Esta composição é semelhante para os ovos de codorna (CLOSA et al., 1999), que são também bastante consumidos no Brasil.

Embora as tabelas de composição centesimal especifiquem os teores de macronutrientes e de colesterol em gemas, claras e em ovos preparados de diferentes formas, normalmente não existem indicações a respeito do tipo de ovo de galinha analisado. Além disso, estão sendo oferecidos, no

* Professora titular, Instituto de Biotecnologia, Departamento de Ciências Biomédicas, Universidade de Caxias do Sul (UCS), Rio Grande do Sul. (e-mail: msalvado@ucs.tche.br).

** Bolsista de Iniciação Científica, UCS, RS. 
comércio, ovos com teores reduzidos de colesterol e ovos PUFA ômega3 , obtidos pelo enriquecimento das rações das aves com produtos à base de farinha de pescado rica em ácidos graxos poliinsaturados (PUFA Poly Unsaturated Fatty Acid) do tipo ômega-3.

Este trabalho teve por objetivo comparar os teores de macronutrientes e de colesterol em ovos com teor reduzido de colesterol, ovos enriquecidos com PUFA ômega-3, ovos vermelhos de galinhas de granja e caipiras, ovos brancos de galinhas de granja, e ovos de codorna.

\section{MATERIAL E MÉTODOS}

\subsection{AMOSTRAS}

Foram analisados 6 grupos de amostras, formadas por diferentes tipos de ovos, ou seja, grupo 1, ovos brancos; grupo 2, ovos vermelhos de galinhas de granja; grupo 3, ovos vermelhos de galinhas caipiras; grupo 4, ovos enriquecidos com PUFA ômega-3, grupo 5, ovos comercializados como contendo "menos colesterol" e grupo 6, ovos de codornas. Cada grupo foi composto por três amostras e cada amostra por 6 ovos. Todos os produtos foram adquiridos no comércio local (Caxias do Sul - Rio Grande do Sul) e encontravam-se de acordo com os prazos de validade estabelecidos pelo fornecedor.

\subsection{MÉTODOS}

Para a determinação dos teores de umidade, de proteínas e de lipídios foram utilizados ovos inteiros, crus e sem casca e para a determinação de colesterol, apenas as gemas. A homogenização das amostras foi feita em liquidificador, durante 10 minutos.

\subsubsection{Determinação de colesterol}

O teor de colesterol foi determinado pelo método fotocolorimétrico proposto pela AOAC (1998). A extração dos lipídios foi realizada a partir de gemas desidratadas em estufa específica. Cada amostra permaneceu por 5 horas em aparelho extrator de lipídios (VELP), utilizando-se clorofórmio como solvente. Os resultados foram expressos em mg de colesterol por $100 \mathrm{~g}$ de gema. 


\subsubsection{Determinação de proteínas}

A percentagem de proteínas foi calculada multiplicando-se o valor médio da percentagem de nitrogênio total pelo fator 6,25 . O teor de nitrogênio total das amostras foi determinado pelo método de Kjeldahl, de acordo com a AOAC (1998).

\subsubsection{Determinação de lipídios totais}

A determinação de lipídios foi realizada de acordo com as normas analíticas do INSTITUTO ADOLFO LUTZ (1985) e a extração em aparelho extrator de lipídios Soxhlet (VELP), durante 2 horas.

\subsubsection{Determinação de umidade}

Determinou-se a umidade a $105^{\circ} \mathrm{C}$, em balança para determinação de umidade por infravermelho (GIBERTINI, precisão de 0,0001 g). Para cada amostra foram feitas três repetições e foi calculada a média aritmética final.

\subsection{ANÁLISE ESTATÍSTICA}

Os resultados obtidos foram submetidos à análise de variância e após ao Teste de Tukey. A análise multivariada incluiu o cálculo das distâncias Euclidianas médias e a análise dos componentes principais 1 (teor de macronutrientes) e 2 (teor de colesterol) de todas as amostras ensaiadas. A formação de grupos foi realizada pelo método de Tocher e confirmada pelo método do vizinho mais próximo (RAO, 1952).

\section{RESULTADOS E DISCUSSÃO}

Os valores resultantes das determinações percentuais de proteínas, lipídios, umidade e colesterol dos ovos analisados são apresentados na Tabela 1. Não foi verificada diferença estatística significativa entre os teores de proteína dos diferentes tipos de ovos. O percentual de lipídios mostrouse maior nos ovos de codorna, seguido pelo dos ovos vermelhos de galinhas caipiras. Os valores mais baixos de colesterol foram obtidos nos ovos comercializados como contendo "menos colesterol". Esta diferença, no entanto, não apresentou significância estatística, provavelmente como conseqüência de grandes variações encontradas dentro do mesmo grupo. 


\section{TABELA 1 - TEOR DE MACRONUTRIENTES E DE COLESTEROL DAS DIFERENTES AMOSTRAS DE OVOS}

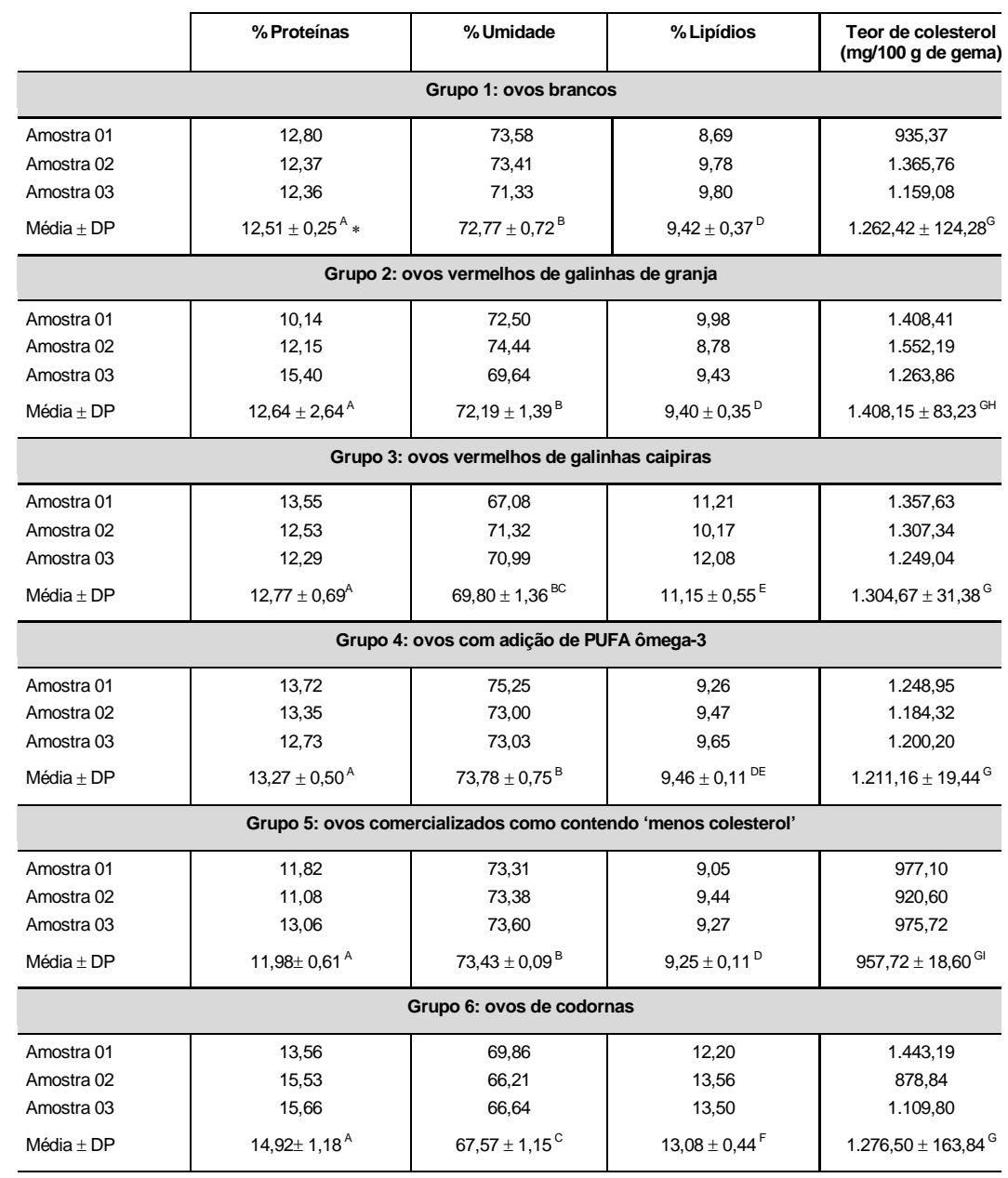

* Valores seguidos por letras distintas são significativamente diferentes pelo Teste de Tukey $(p<0,05)$.

$\mathrm{DP}=$ Desvio padrão. 
Os resultados obtidos corroboram os citados por BEYER e JENSEY em 1991 e por GUEDES, SILVA e SOARES, em 1992, que demonstraram oscilações nos percentuais de colesterol dos ovos de 1.033 até $1.862 \mathrm{mg} / 100 \mathrm{~g}$ de gema. Tal variação pode ser explicada em função da linhagem, estação do ano, idade, número de ovos/dia e, principalmente, pela alimentação oferecida às aves (CLOSA et al., 1999).

Já está comprovado que, no homem, a ingesta regular de PUFA ômega3 diminui o nível plasmático de triglicerídios e aumenta o do colesterol high density lipoprotein (EDINGTON et al., 1987; EDINGTON et al., 1989; OH et al., 1991; GARWIN, 1992; JIANG e SIM, 1993). Embora o consumo de alimentos enriquecidos com estes ácidos graxos possa ser benéfico para o homem verificou-se que os ovos provenientes de aves alimentadas com rações enriquecidas com PUFA ômega-3 não apresentaram reduções significativas nos teores de lipídios ou de colesterol (Tabela 1).

Com o objetivo de complementar a avaliação dos dados obtidos, os resultados foram submetidos também a análise estatística multivariada, a qual permitiu a separação de 3 grupos similares: (a) ovos brancos, ovos vermelhos de galinhas de granja e caipiras; (b) ovos enriquecidos com PUFA ômega-3 e os com teor reduzido de colesterol e (c) ovos de codorna (Figura 1).

\section{FIGURA 1- ANÁLISE MULTIVARIADA DO TEOR DE MACRONUTRIENTES E DE COLESTEROL DOS DIFERENTES TIPOS DE OVOS}

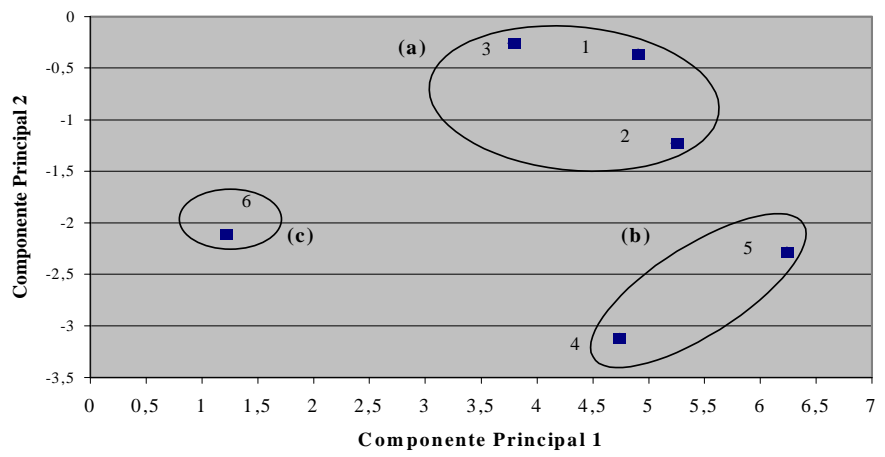

1 = ovos brancos; 2 = ovos vermelhos de galinhas de granja; 3 = ovos vermelhos de galinhas caipiras; 4 = ovos enriquecidos com PUFA ômega-3; 5 = ovos comercializados como contendo "menos colesterol" e 6 = ovos de codorna. 
Os resultados obtidos neste trabalho podem contribuir para a elaboração de dietas que incluam a ingesta de alimentos como fator de risco, como é o caso dos ovos.

\section{CONCLUSÃO}

Não foi observada diferença estatística significativa entre os teores de proteína dos ovos analisados. O maior percentual de lipídios foi encontrado em ovos de codorna. Os valores de colesterol oscilaram bastante dentro de alguns grupos, levando à ausência de diferença estatística significativa entre os diferentes tipos de ovos. A análise multivariada permitiu a formação de 3 grupos com resultados similares: (a) ovos brancos, ovos vermelhos de galinhas de granja e caipiras; (b) ovos enriquecidos com PUFA ômega3 e ovos comercializados como contendo "menos colesterol" e (c) ovos de codornas.

\section{Abstract}

MACRONUTRIENTS AND CHOLESTEROL CONTENT IN DIFFERENT TYPES OF EGGS

The macronutrients and cholesterol content were evaluated in red and white eggs, eggs enriched with PUFA $\sigma-3$; white eggs with low cholesterol content and quails eggs. The results showed that there wasn't any significant statistical difference between protein and cholesterol content of the analysed eggs. The quails eggs demonstred higher lipid content of the evaluated samples.

KEY WORDS: EGGS; CHOLESTEROL.

\section{REFERÊNCIAS}

1 AOAC. Association Official Agricultural Chemists. Official methods of analysis of AOAC international. $16^{\text {th }}$ ed. Washington, 1998. Cap. 34, p. 2.

2 BEYER, R. S.; JENSEY, L. Influence of orotic acid on performance, liver lipid content and egg cholesterol level of laying hens. Poult. Sci., v.70, n.11, p. 2322-2328, 1991.

3 CLOSA, S.J.; MARCHESICH, C.; CABRERA, M.; MORALES, J.C. Composición de huevos de gallina y codorniz. Arch. Lat. Nutrición, v. 49, n. 2, p.181-185, 1999. 
4 EDINGTON, J.; GEEKIE, M.; CARTER, R.; BENFIELD, L.; BALL, M.; MANN, J. Effect of dietary cholesterol on plasma cholesterol concentration in subjects following reduced fat, high fibre diet. Br. Med. J. Clin. Res., v. 194, n. 6568, p. 333-336, 1987.

5 EDINGTON, J.; GEEKIE, M.; CARTER, R.; BENFIELD, L.; BALL, M.; MANN, J. Serum lipid response to dietary cholesterol in subjects fed with a low fat, high fibre diet. Am. J. Clin. Nutr., v. 50, n. 1, p. 5862, 1989.

6 GARCÍA, C.;ALBALA, C. Composición lipídica de huevos de gallinas alimentadas con productos grasos y proteicos marinos. Arch. Lat. Nutricion, v.48, n.1, p.71-76, 1998.

7 GARWIN, J. L. Modified eggs are compatible with a diet that reduces serum cholesterol concentration in humans. J. Nutrition, v. 122, p. 2153-2160, 1992.

8 GUEDES, L.S.; SILVA, K.M.da; SOARES, M.G.C.B. Cholesterol and phospholipids content of yolk from fertilized and unfertilized hen eggs. Brazilian J. Med. Biol. Res., v.25, p. 327-329, 1992.

9 INSTITUTO ADOLFO LUTZ. Normas analíticas do Instituto Adolfo Lutz: métodos físicos e químicos para análise de alimentos. 3. ed. São Paulo, 1985.533 p.

10 JIANG, Z.; SIM, J. S. Consumption of n-3 polyunsaturated fatty acidenriched eggs and changes in plasma lipids of humans subjects. Nutrition, v.9, n.6, p.513-518, 1993.

11 MADRID, A. Manual de industrias alimentarias. Madrid: MundiPrensa, $1981.565 \mathrm{p}$.

$12 \mathrm{OH}, \mathrm{S} . ;$ RYUE, J.; HSIEH, C.H.; BELL, D. E. Eggs enriched in omega3 fatty acids and alterations in lipid concentrations in plasma and lipoproteins and blood pressure. Am. J. Clin. Nutr., v. 54, n. 4, p. 689-695, 1991.

13 RAO, C. R. The concept of distance and the problem of group constellations. In: RAO, C. R. Advanced statistical methods in biometric research. New York: J. Wiley, 1952. p. 351-378. 


\section{Agradecimentos}

Os autores agradecem a colaboração do Prof. Dr. Sérgio Echeverrigaray e da Universidade de Caxias do Sul (UCS), RS. 